\title{
Viewpoint: Integrating CRM (Coordinated Resource Management) and NEPA (National Environmental Policy Act) processes
}

\author{
SHERMAN SWANSON
}

\author{
The author is associate professor in the Department of Environmental and Resource Sciences, University of \\ Nevada, Reno 89512.
}

\begin{abstract}
Coordinated Resource Management (CRM) and the National Environmental Policy Act (NEPA) each provide an approach for involving the public and resource specialists from many disciplines in public land management decisions. This viewpoint suggests combining the consensus building approach of CRM into the broader public involvement and sometimes more thorough analysis of a NEPA process. The combined process seems most applicable when a diversity of interests want potentially incompatible decisions, especially if those decisions could significantly affect the structure and function of ecosystems or natural-resource-based economies. Fourteen steps in a combined process describe the mechanics and rationale for this integration. To succeed with this process, begin with thorough preparation, then fostor open and repeated 2-way communication. Communication with the broader public ensures that all affected interests may contribute ideas. Consensus building with representatives of all resource interests and land ownerships ensures public trust and broadly supported management. Consensus building continues through decision making, implementation, monitoring, evaluation, and replanning.
\end{abstract}

Key Words: planning, public land, alternative dispute resolution, public involvement, and environmental analysis

The Extension Service, Soil Conservation Service, and the Forest Service in USDA and the Bureau of Land Management in USDI sanctioned Coordinated Resource Management in memoranda of understanding in 1980 and 1987. Coordinated Resource Management (CRM) “provides for interaction among interested and affected agencies, organizations, individuals, and the planning agency to determine mutually acceptable management practices and multiple use objectives at the local level" (MOU 1987 in Phillippi and Cleary 1993). Through CRM people in many states and provinces have resolved public and private land management questions with much success. It's become an effective tool for improving public involvement and enlightened interdisciplinary management.

The National Environmental Policy Act (NEPA) became law in

The NEPA process refers to how Federal agencies analyze the environmental effects of certain proposed actions. They must involve the public and document their analysis in an Environmental Assessment (EA) and/or Environmental Impact Statement (EIS). (See Council on Environmental Quality 1986.)

The author wishes to thank Rex Cleary, E.W. (Bill) Anderson, Dave Torell, Edith Asrow, Tony Dana, Mike Havercamp, Glen Sechrist, Robert Larkin, John Butt, and Craig Whittekiend for their significant contributions to my thinking regarding this integration and for their editorial help. In part, this viewpoint reflects the experience of and lessons learned from the Modoc-Washoe Experimental Stewardship Program. However, the responsibility for any errors or omissions rests entirely with me.

Manuscript accepted 17 Sep. 1993.
1970. It requires Federal agencies to use a systematic and interdisciplinary approach for environmental analysis and decision making. Agencies must document the process with environmental assessments (EAs) or environmental impact statements (EISs). Procedures for implementing NEPA ensure that public officials and citizens have environmental information available before making decisions and taking actions. "Accurate scientific analysis, expert agency comments, and public scrutiny are essential to implementing NEPA" (Council of Environmental Quality 1986).

Because public lands are held in public trust, many laws (The Federal Land Management and Planning Act, National Forest Management Act, and others) require public involvement in management decisions for these lands. Court decisions and policies interpreting these laws have modified management procedures and given the public more opportunities to be involved early and in meaningful ways.

Many peoples'livelihoods depend on the management of public lands. Furthermore, many actions by private citizens affect the public's resources. This is especially true in lands grazed by livestock. The rancher, operator, or herder is often the most critical land manager on a day-to-day basis. Other examples abound of management actions influenced or caused by private citizens, including volunteer projects, advisory or support coalitions, and people with a concern for certain natural resources. Substantial knowledge about public land ecosystems and socioeconomics resides with the public, outside administering agencies.

Public land managers who believe in the public involvement and interdisciplinary philosophy behind either CRM or NEPA find the 2 processes compatible. When integrated, and facilitated by people skilled in communications and public involvement, these processes strengthen each other. Together CRM and NEPA ought to produce better plans and better land and resource management.

However, public land administrators who believe the agency knows best, or who become frustrated with consensus building or open dialogue, will find the integration of CRM into NEPA difficult. They may frequently frustrate the public's desire for meaningful involvement even when following the NEPA process. This paper expresses my viewpoint that integrating CRM into the NEPA process often improves both public trust and environmental and resource management decisions. It provides rationale and outlines some essential steps in the process.

\section{The NEPA and CRM Processes}

Agencies have developed detailed guidelines for the NEPA process including the required public involvement. Decisions and 
actions must be based on sound technical information about environmental, economic, social and other considerations. Agencies must identify and consider environmental effects of proposed actions as well as a reasonable range of alternate solutions or actions. Alternatives often include no change in present management and ones that address issues and concerns inadequately addressed by the proposed action but that would accomplish stated goals and objectives. The relationship between short-term uses and the maintenance and enhancement of long-term productivity must be considered. The NEPA process must identify and consider any unavoidable adverse effects and any irreversible or irretrievable commitments of resources. However, the agency need not select the alternative with least impact.

Existing environmental impact statements (EISs) and environmental assessments (EAs) document much of this process of environmental analysis. However, the requirement for a NEPA process is ongoing. Any proposed Federal actions "significantly effecting the quality of the human environment" not having previous environmental documentation must be analyzed. Although this will not include all Coordinate Resource Management plans, even on Federal land, it may include most with Federal involvement.

Meanwhile, Coordinated Resource Management (CRM) has evolved as a form of public involvement informally combined with interdisciplinary and interagency coordination. "Coordinated Resource Management is an approach for reaching decisions and resolving resource conflicts"(CRM Memorandum of Understanding 1987 in Phillippi and Cleary 1993). It is a voluntary process in which natural resource owners, managers, and users work together as a team. Coordinated Resource Management teams formulate and carry out plans for the management of all major resources and land ownerships in a planning area, or they resolve specific conflicts. Critical elements of CRM include: (1) participation by the full diversity of people, land owners, groups, and agencies interested in the land and its resources, uses, and values; (2) equal opportunity for developing ideas and resolving issues through consensus; and (3. becoming committed to resolving issues by focusing on collective needs and the opportunities inherent in the land and its resources. Through coordination, the management of different resources and the land ownerships becomes integrated into 1 plan with common objectives.

Our society faces great challenges relating to changes in values, economic or ecologic realities, ideas, knowledge, and ownership of knowledge. One cannot assume that either old or new ideas are automatically better. Neither can one assume that agencies necessarily possess the best information about some resources. Although public involvement and environmentally conscientious decision making are both necessary in public land management, the processes used to achieve them have not always been ideal. By taking steps to become fair and thorough, some processes may be too bureaucratic, costly, and time consuming. Analysis of unrealistic alternatives or consequences adds to this perception. Some of the public, who should be actively involved in decision making, become frustrated. They lack confidence that agencies take scriously the ideas provided in formal public hearing or calls for written comment. Often they fail to understand the kind of information that could be most useful. In contrast, processes that emphasize collaboration with only selected individuals or groups may achieve responsiveness at the expense of objectivity. Some interested parties become alienated by a process they perceive as unfair or user unfriendly. They become bitter about decisions they cannot accept, but cannot afford to challenge in court.

To avoid this, and to achieve optimum efficiency, openness, and thoroughness in both public involvement and environmental analysis, I suggest an integration of CRM in NEPA processes. The combined process seems most applicable when different interests want potentially incompatible decisions. This is especially true if the decision significantly affects the structure and function of ecosystems or natural-resource-based economies.

\section{Integration of NEPA and CRM}

As land managers learn of the legal and practical mandate to follow the NEPA process, some see those well-defined guidelines as the only acceptable steps in the decision making process. However, NEPA was intended to be an environmental analysis and disclosure process not a decision making process.

Some land managers believe in the openness of CRM. They emphasize the ability within CRM to develop understanding among previous adversaries and commitment for carrying out truly coordinated plans. Unfortunately CRM advocates sometimes fail to grasp the necessity of NEPA. A good NEPA process will often produce a technically stronger decision because of mandated thoroughness (including analysis of alternatives). Coordinated Resource Management advocates should also realize that some legitimately affected interests cannot or will not become involved in a sometimes inconvenient, lengthy, or time consuming CRM process.

This paper provides a format that unites CRM and the NEPA process (Fig. 1 \& Steps 1-14). The strengths of each process should lead to better decisions and better land and resource management. The strengths of an integrated process can help avoid weakness of each individual process.

Although neither CRM nor NEPA is restricted to public land, the setting for this united process often involves some public land. Land management does not begin at a point in time, but is an ongoing process. It is crucial that land managers learn from successes and failures. As new knowledge and philosophies develop, proactive managers, users, and other interested parties share their thoughts. At times, they see the need for new management, or a coordinated set of decisions regarding a specific land area. The need for new management is clear on some public rangelands. Evaluations of monitoring information have suggested real problems with existing management in places. In some areas there is inconsistency between on-the-ground management and new landuse plans (National Forest Land and Resource Management Plans or Bureau of Land Management Resource Area Management Plans). Open communication through the years minimizes the surprise of such needs.

The process described here primarily applies to plans at a smaller scale than the "National Forest" and "Resource Area" plans mentioned above. The appropriate area for a CRM/NEPA plan could be an allotment, several allotments, a watershed, mountain, or any other logically defined site-specific management area. However, when a plan for a whole National Forest or Bureau of Land Management Resource Area needs revision, a similar process could be used. The major difficulty with consensus decision making in such broad-scale planning efforts is the large number of people who want to be involved, and the sometimes political nature of those decisions.

\section{Steps to Follow in an Integrated CRM/NEPA Process}

I have described below (steps 1-14 and Fig. 1) an integrated CRM/NEPA process with rationale and guidelines. Although steps are presented in sequential order, efficient managers anticipate and prepare for future steps. A few steps go on simultaneously. Failure to plan ahead and progress steadily will convince some that CRM, NEPA, or the government is too bureaucratic or their involvement is not valued.

\section{Step 1: Initiate $C R M$}

When an agency, land owner or operator, interested citizen, or 


\section{ANNOUNCE}

SCHEDULE

\section{SOLICIT PUBLIC INPUT, INPUT}

INITIATE CRM

(staff prepares)

ANALYZE THE MANAGEMIFNT SITUATION

(form ID team to write pre-tour packet)

SELECT/RECRUIT CRM TEAM MEMBERS

SELECT/RECRUIT FACILITATOR

SEND INFORMATION TO CRM TEAM

TOUR PLANTING AREA

(form CRM team, learn the land,

\& share perspectives)

DEVELOP THE CRM PLAN

(develop goals, objectives \&

management actions by consensus

with help from facilitator \& ID

team. Then sign the CRM plan)"

SEND PROPOSED

ACTION TO

PUBLIC FOR

COMMENT

SEND DECISION

NOTICE TO

PUBLIC
REVIEW AND APPROVE

(by steering committee if any)

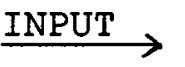

CONTINUE SCOPING

DOCUMENT NEPA ANAIYSIS

(consider comments \&

alternatives, then write EA)

minor $>$ ISSUE A DECISION

changes (sign EA with a FONSI \&

needed write decision notice)

$\underset{\text { (if anY })}{\stackrel{\text { aPPEALS }}{\longrightarrow}}$

CONSIDER APPEALS

( IMPLEMENT AND MONITOR

EVALUATE

r REPLAN
USE OTHER

PLANNING OR RESOURCE

MANAGEMENT

PROCESS
USE OTHER

PLANNING OR

RESOURCE

MANAGEMENT

PROCESS

SIGNIF-

ICANT

CHANGES

TO CRM

PLAN

NEEDED

\section{OR FILE A NOTICE \\ OF INTENT \\ TO FILE AN EIS}

Fig. 1. Flow chart showing an integration of CRM and NEPA-mandated environmental analysis and documentation. The CRM team does the process steps in italies. The center column lists the principal steps in the process.

*After a proposed action has been through scoping, and based on comments or appeals the CRM team has come to a new consensus, only writing an EA precedes issuing a decision.

group such as a Conservation District realizes the need for a new plan, they may request that others work with them to help develop it. Often agencies have a prioritized schedule of areas that need new management or a coordinated set of decisions. After any discussion of needs or schedule adjustments, community, agency, and interest group leaders agree that it is time to get started. Experimental Stewardship Programs (set up under the Public Rangelands Improvement Act) established steering committees. These steering committee and similiar umbrella-type CRM groups generally decide when to start planning on particular areas or resource issues. Where the management and activities of several people or agencies should be coordinated. the olanning area often includes more than one land ownership. Generally, the agency responsible for management of the largest land area takes a primary role. When the area includes the land of more than one Federal agency, each may do at least some of the primary-agency functions.

\section{Step 2: Analyze the Management Situation}

Successful planners use the best available information. To prepare an analysis of present management and resource conditions and interdisciplinary team (ID team) forms within the primary agency. Resource specialists with skills nceded to address the important resource issues and uses compose the ID team. Their analysis describes the existing condition of the resources. and 
resource management issues, concerns, or opportunities. The desired future condition (according to the Forest Plan or Resource Management Plan) describes the goal. Furthermore, the analysis includes possible management practices with preliminary comments about their direct, indirect, and cumulative environmental, economical, economic, and other consequences. The analysis also lists affected Federal, state, and local agencies and other interests. Input comes from resource specialists inside and outside the agency, monitoring and historical records, reports, inventories, planning documents, research, etc., and the public. To learn the concerns of the public, the primary agency publicizes anticipated planning efforts and solicits public input with press releases, letters, public meetings, tours, personal contacts, etc., as appropriate. When completed, the analysis becomes the core of a packet sent to all potential CRM team members.

Although such an analysis is necessary, its preparation often generates fear among those who feel threatened by change. Therefore, it's important to word the document positively and make it informative without allowing it to become argumentative or advocacy oriented.

\section{Step 3: Select/ Recruit CRM Team Members}

When the ID team and others are ready for active planning, the steering committee recruits appropriate people (or groups to be represented) for the CRM team. Lacking a steering committee, a Conservation District or a few "community pillars" and the primary agency, land owner, or permittee(s) can invite participation. The primary agency will know, through previously invited public input, of certain individuals or groups with the knowledge and skills needed to represent various interests.

The CRM team consists of field level professionals appropriate for the types of resources and existing conditions, opportunities, and conflicts. It consists of: (1) a representative from the agency(ies) responsible for managing the public land; (2) expertise from other directly involved agencies (such as the state fish and wildlife department or the Soil Conservation Service); (3) representatives from environmental interest groups or individual(s) who understand their concerns; (4) involved permittees and any included land owners or their representative(s); and (5) individuals who can represent other appropriate interest groups (wild horse, off-road vehicle, etc.) that want to, or should be, involved. Adequate and complete representation of all resource interests and all land ownerships is vital to successful CRM.

Leaders may have to recruit certain people or interests with needed expertise or perspective. They may also have to screen out dysfunctional personalities, people who cannot adapt to the requirements of communication and teamwork. Some such highly vocal personalities have strong interests that should be represented by someone else who can effectively participate in a team effort. If key interests do not represent themselves, the CRM team should still consider their concerns. The primary agency should represent all legitimate interests (national, regional, local, future generations, and taxpayers), even in their absence. To maintain continuity, if the CRM team is to update the work of a prior CRM plan, prior CRM team members should be recruited if practical.

\section{Step 4: Select/Recruit a Facilitator}

The primary agency, with the help of the steering committee or key people, should recruit an appropriate unbiased facilitator or moderator familiar with the CRM process. The skills needed by the facilitator will include meeting management, communication, role clarification, team building, working with diverse audiences and sometimes difficult people, visioning, goal and objective setting, decision making, and group maintenance. Various training materials discuss CRM effectiveness and meeting facilitation (Ander- son and Baum 1988, Phillippi and Cleary 1993). Also, much has been written about effective alternative dispute resolution (Fisher and Ury 1983, Bingham 1986, Ury 1991, Rees 1991, and Hart 1992). The team must come to trust the facilitator and believe that he or she will help them all make timely progress.

\section{Step 5: Send Information to the CRM Team}

The primary agency sends a pre-tour packet (see step 2 above) to each CRM team member at least 2 weeks before their first meeting. This packet should contain maps of the planning area and details about its physical, biotic, and cultural features. There should be a description of present management, a summary of important inventories and monitoring information, and pertinent information on management const raints or desired future conditions from any applicable Forest Plan or Resource Management Plan. To this is added an array of possible management practices and comments about them, and any other pertinent information.

The packet is not intended to resolve issues. However, it will provide information needed for the CRM team to resolve them. It should be clear that the CRM team will be free to develop their own solutions for resource management in the planning area. They may use all or parts of the listed possible management practices or develop completely new ideas. If they succeed in developing a plan by a consensus, it will become the "proposed action" upon which the primary agency will conduct any needed environmental analysis (the NEPA process).

The packet will naturally focus attention on key unresolved issues. Although a necessary tool for management, this information may make the process of visioning more difficult. To overcome this, the facilitator may need to begin by emphasizing relationship building and goal setting. This will help avoid premature debate of analysis-implied problems or solutions that may become irrelevant with a new vision and evolving management strategy.

The primary agency also sends the CRM team a description of the CRM process. The steering committee or someone familiar with the CRM process normally develops this paper. Some states have a handbook for this purpose. The CRM Handbook published by the Society for Range Management contains appropriate descriptive materials (Phillippi and Cleary 1993). This description explains how members will be involved and for what they should prepare. Coordinated Resource Management team members should read the CRM materials and study the packet of information before the first team meeting.

\section{Step 6: Tour the Planning Area}

To work as an effective team, members of the CRM team prepare themselves. They will each need to become familiar with the landscape and resource features of the planning area as well as opportunities for improved or continued resource management. For many CRM teams, their first meeting is a tour of the planning area. Participants learn first hand the nature of the resources, opportunities, and conflicts. They check the completeness and accuracy of any perceptions based on information in the pretour packet. Additional information about the planning area is added as necessary during or after the tour.

As team members with different and often conflicting interests describe their vision for the land, they tell others what motivates or concerns them and why. Everyone on the team, because of their different experiences, brings a unique set of viewpoints to the team. Each will probably identify opportunities, conflicts, and resources that the others might overlook. Thus they begin an informal process of building relationships with other team members as they share personal knowledge of the land and its uses.

The CRM team tours the planning area by vehicle, on foot, or by horseback. Size of the area and the complexity of the situation 
dictate the time required. The minimum time is usually one day. It is important to look at the entire planning area and not just the main or important parts of it.

To provide timely and useful participation, and to negotiate effectively, team members should understand key features of the CRM process including the meaning of consensus. At the beginning of the tour, a representative of the Steering Committee or primary agency explains expectations for the whole process. It should be clear how the primary agency will support a consensus and that environmental analysis and public review must follow.

Then the facilitator explains, or develops with the group, the ground rules and operating procedures. The facilitator might discuss group process for working through difficult issues, steps for building trust, and relationships with others including the media. Each team member should discuss their role and be familiar with it. They should also discuss a time line so participants can commit the necessary time. Some CRM teams summarize these discussions at the beginning of the tour and conduct a thorough follow up at the start of the first indoor meeting. Some also conduct a wellorganized training that describes the process in detail. Such training also describes what the process is not, and how it has been successful elsewhere.

When discussions lead to consensus about an action item it must be recorded so that all can agree that it is the action they agree to. Recording agreement items promptly, while everyone is present, is critically important. Ideas are clear in everyone's mind and receive full team support. Occasionally a CRM team develops a consensus about a complete and thorough set of recommendations during discussions on the field tour. More often, the tour becomes the foundation for considerable follow up consensus building. Working through conflicts to arrive at consensus is part of the CRM process.

\section{Step 7: Develop the CRM Plan}

Through continued meetings the team will come to understand the purpose, role, and most important issues and concerns of each team member. The lead agency and other representatives will help them become familiar with pertinent laws, policies, opportunities, and constraints. During CRM, team members will each need to:

-explain their needs and listen to (learn) the needs of others;

-participate in team building to develop mutual trust;

-help develop common goals and objectives based on issues, concerns, and opportunities;

-keep constituents up to date on meetings and decisions;

-consider input to the plan from outside the CRM team;

-work toward solving problems;

-propose, with others, an integrated set of actions to accomplish the goals and objectives.

All CRM team members make personal decisions regarding when to negotiate for something different and when to accept alternate ideas that others feel strongly about. In many situations, expressions of discomfort with a proposal lead to further discussion and better solutions. A solution not previously thought of will often meet the needs of all parties and therefore not require a compromise.

To develop a team concept of the vision for the land and the CRM Plan, the first meeting soon after the tour should focus on goals. It is critically important for the group to create a vision and move forward with faith, motivation, and commitment. By starting with perceptions of opportunities and then of issues or problems, the team may find the common interests and trust to state goals expressing collective agreement. Each person should explain their needs as opposed to a bargaining position. Some teams prefer to discuss resource needs and their vision before a field trip, as a way for people to get to know each other.
Goals express a general direction and may depict a condition desired far into the future. They may not be worded precisely enough to identify the needed management actions and monitoring information. Thus the team develops specific objectives that address the stated goals. The time needed to accomplish objectives should be consistent with the length of the planning cycle.

Management actions should be based on specific objectives that provide enough detail to identify needed monitoring. It should be apparent for each objective who will measure success or failure and how. For example, describing the desired plant communities focuses ideas that help to choose appropriate management actions and vegetation monitoring methods. A good objective is obtainable, measurable, and worthy of the management cost (including monitoring) necessary to achieve it. To ensure consistency, the team should develop specific objectives and management actions at the same time.

It is critically important that the interdisciplinary (ID) team knows of the CRM team's progress and concerns and makes available any needed analysis. The interdisciplinary team members should actively participate in the tours and meetings as needed. The CRM team should have and use the best collective wisdom as the basis for their recommendations. If the primary agency receives additional important information or a request from the public, the agency has an obligation to help the CRM team address the need. Similarly, if ID team members have a problem with developing ideas, the CRM team should learn of the concerns carly enough to address the issue.

Note that in each Federal agency, a responsible official (such as a Forest Service District Ranger or Bureau of Land Management Area Manager) makes the final decision on proposed actions that affect public lands. The responsible official (after discussions with ID team members) may not agree with the evolving CRM consensus. If CRM representatives anticipate official disagreement, they prevent misunderstanding or mistrust by improving communications. Decision makers and other key individuals with strong views should be encouraged to present their views on specific matters and to listen to the views of others. It helps for the responsible official, and the decision makers of other groups, to personally participate in CRM meetings. When decision makers do not participate, they must trust their selected representative. Representatives on the CRM team should discuss ideas as needed with those they represent. However, all team members need the flexibility to explore the wide range of potential solutions, and to accept any that meet the breadth of participants' needs and their common goals.

Groups may fail to reach consensus at times. They can and should use many strategies to work through the impass. Scheduling additional field time, bringing in technical expertise, and providing time for people to collect their thoughts, consider alternatives, or create new ideas all help. However, the team needs to understand that decisions must be made. If the team cannot resolve the issue in a reasonable time, responsible officials and land owners may have to make decisions without the benefit of the team's recommendation. However, as long as the team continues to progress in a good-faith effort, decision makers should make every effort to allow their work to go on. Usually, there is much the team agrees upon. Often, management can move forward even when the team hasn't resolved all issues.

When the CRM team members all agree that the plan (the collective set of actions) adequately addresses all goals and objectives, all members signify mutual support and agreement by signing it. They then receive a copy of the agreed upon CRM plan. Items in the plan include sufficient details about such things as grazing strategies, proposed range or habitat improvements, monitoring, and any other actions the group will take for resource management on the planning area. All agreed upon actions should 
state or list who will do what, where, and when.

\section{Step 8: Review and Approve}

The responsible official then approves the CRM plan as concurrently or subsequently, but informally, analyzed by the ID team. Where appropriate, the responsible official approves it as a member of a steering committee or umbrella group. These groups also function by consensus. If the steering committee or responsible official(s) do not concur, they send the report back to the CRM team. After reconciling the concerns, the CRM team again brings their recommendations to the responsible official or steering committee for approval. The approved CRM plan becomes the proposed action for additional scoping and completion of any required environmental analysis.

The role of the responsible official(s) on the steering committee warrants explanation and emphasis. The responsible official is clearly responsible for the decision. The official can neither shift nor share the responsibility. However, the decision-making process can be shared. Therein lies a unique and invaluable characteristic of CRM. Federal advisory boards and committees develop advice and recommendations for the responsible official who later weighs the advice while making a decision. In contrast, the responsible official who is a member of a CRM steering committee works shoulder to shoulder with other members rather than accepting advice from a distance. Participating responsible officials in no way shift responsibility, but do share the process. Agency staff functions in much the same way on the CRM team. The manager participates with the advisors rather than just listens. This characteristic, which is unique to CRM, explains much of the success that CRM has enjoyed. The Experimental Stewardship Program is the testing and experimental ground for CRM and the effect of this unique quality is central to the success reported for this process in the 1985 and 1991 Reports to Congress (USDA and USDI 1985 and 1991).

\section{Step 9: Continue Scoping and Document NEPA Analysis}

Scoping is a required process for identifying the scope of significant issues related to a proposed action. It invites additional participation from the public and other agencies. Interdisciplinary team communications with the public and the CRM process achieve much of the purpose for scoping. However, formal scoping is based on a proposed action, the CRM plan.

Following steering committee consensus or responsible official approval, the agency sends a description of the proposed action, to affected interests for review. The description includes initial and future conditions and may include other alternatives considered. An enclosed letter encourages the public to provide comments. The public may offer information, support, or criticism, or request analysis of additional alternatives.

Public comment may cause the responsible official(s) to prefer management actions different from the proposed action. If peferred management significantly differs from the CRM plan, the CRM team or steering committee needs to meet. Together they work out any differences by developing (a new?) consensus if possible.

The agency documents an analysis of the proposed action and any appropriate alternatives in an environmental assessment (EA). To keep EAs concise, they should tier to, adopt, or incorporate by reference other environmental documents (US Forest Service 1992).

\section{Step 10: Issue a Decision}

With a completed environmental assessment, the responsible official selects a preferred alternative. This may be the original proposed action or a new alternative endorsed by the CRM team (and steering committee where appropriate). If the CRM team could not agree on an alternative that meets the agency's responsibilities, the responsible official may have to select an alternative not endorsed by the CRM team. However, such a decision often leads to court and may make working with affected interests very difficult.

After selecting the preferred alternative, the responsible official determines if the proposed action will have a significant impact on the "human environment" based on the completed environmental assessment. If not, the official issues a "finding of no significant impact (FONSI)"' and a concise decision notice that describes the preferred alternative. The agency then notifies interested and affected people, other Federal agencies, state and local governments, and organizations of the availability of environmental and accompanying decision documents. The primary agency may then write these decisons into any other plans as necessary (for example by writing allotment management plan(s) in consultation with the permittee(s)).

\section{Step 11: Consider Appeals}

Following the decision notice, anyone may request a copy of the environmental assessment. Experience has shown that open planning processes reduce opposition and appeals, especially after CRM consensus building. However, some issues are intractable and any affected interest may appeal the decision. If the appeal is upheld, sometimes only minor modification is needed and this may not require calling the CRM team back together. However, if significant modifications are warranted, reconvening the CRM team becomes the logical next step.

\section{Step 12 Implement and Monitor}

Once a plan is complete, managers should carry it out as soon as possible or as specified in the plan. This is why the original (and any subsequent) CRM plan identified responsible individuals and a timeline. Timely implementation requires continued CRM team support and possibly meetings or work parties. Some projects in the plan may also require additional detailed planning, such as developing specifications for installing structures. Only those who will directly use or install the project need to design it.

Implementation, effectiveness, and validation monitoring are each needed to learn whether prescribed management was applied and meets objectives. Implementation monitoring tells what actions were taken, including such things as use dates, herd size, dates of project completion, etc. Effectiveness monitoring records the short-term effect of applied management. It includes such things as utilization pattern or residue levels as affected by grazing use and growing conditions. It also records the effect of natural events such as weather, fires, floods, etc. Validation monitoring documents the long-term effect of management. It measures trend in attainment of plan objectives including such things as changes in species composition, growth of woody vegetation, or changes in stream channel form.

\section{Step 13: Conduct Annual Reviews}

Periodic review sessions require monitoring information. The CRM team should meet semiannually or annually. They keep abreast of progress toward implementation, the success of planned actions, and problems or additional needs. Regular meeting are especially important early in the implementation phase. Experience has shown that when key people do not continuc to meet and take management actions by consensus, the plan is likely to fail. Almost every plan needs fine tuning and some may need major

Note that if the responsible official determines that the proposed action will have significant effect on the quality of the human environment. the official issues a notice of intent to file an environmental impact statement (EIS). Often when an EIS is needed, it will be prepared, instead of an EA. An EIS proposed action can also be developed with a CRM process. However there may also be formal public hearings, a more detailed environmental analysis of more alternatives, public review of a draft EIS, and other differences in scale. 
adjustment. The CRM team is the logical group for this. Sometimes, fundamental goals change with time. Whenever a plan needs adjustment, the primary agency may need to supplement or revise environmental analysis and documentation.

\section{Step 14: Evaluate and Replan}

Sometimes new information, the nonattainment of long-term objectives, or a change in goals of the primary agency or other key player(s) creates the need for replanning. In extreme situations, this should be accepted as simply a need to start over at step 6, or rarely step 1 . Whether the primary agency needs to supplement or revise environmental documentation depends on how much the latest plan differs from prior environmentally documented plans.

In conclusion, CRM is most successful when people follow the "cardinal rules for CRM," that is when: (1) all the affected interests were adequately represented, (2) participants expressed their needs (not their positions), (3) the team became committed to success, and (4) they agree to management by consensus (Phillippi and Cleary 1993). Those groups that continue to meet annually and take management actions through the CRM process consistently find that resource management continues to improve (Anderson and Baum 1987). In addition, CRM plans often include nonfederal land and increase the possibility for entire watershed, ranch, habitat, or ecosystem approaches. By combining CRM with the professional staffwork and additional public involvement required by NEPA for Federal lands and actions, planning becomes more thorough and decisions become more defendable. When everyone understands the legal requirements from the beginning, they can understand their role and plan their participation. By combining the NEPA process with the consensus-building CRM process, plans and decisions become better supported and more easily carried out.

\section{Literature Cited}

Anderson, E.W., and R.C. Baum. 1987. Coordinated resource management planning: Does it work? J. Soil and Water Conserv. 42:161-166.

Anderson, E.W., and R.C. Baum. 1988. How to do coordinated resource management planning. J. Soil and Water Conserv. 43:216-220.

Bingham, G. 1986. Resolving environmental disputes, A decade of experience. The Conservation Foundation, Washington D.C.

Fisher, R., and W. Ury. 1981. Getting to yes-Negotiating agreements without giving in. Penguin, N.Y.

Hart, L.B. 1992. Faultless facilitation-A resource guide for group and team leaders. H.R.D. Press, Amherst, Mass.

Phillippi, D. and C.R. Cleary. 1993. Coordinated resource management Guidelines for all who participate. Spec. Pub. Soc. Range Manage., Denver, Colo.

Rees, F. 1991. How to lead work teams-Facilitation skills. Pfeiffer and Co. San Diego, Calif.

Ury, W. 1991. Getting past no; Negotiating agreements with difficult people. Bantam books.

U.S. Forest Service. 1992. National Environmental Policy Act; Revised policy and procedures: Notice of adoption of final policy. Federal Register, 57:43180-43213.

U.S. Department of Agriculture and Interior. 1985. Experimental Stewardship Program Report to Congress. USDA and USDI 67 p.

U.S. Department of Agriculture and Interior. 1991. Experimental Stewardship Program Prog. Rep. Bureau of Land Management, Salmon, Ida. 